\title{
Polioviruses Characterizations and Molecular Marker and their Applications
}

\author{
Abdullah Aljaddawi ${ }^{1,2}$ \\ ${ }^{1}$ Department of Biological Sciences, Faculty of Science; King Abdulaziz University, Jeddah, Saudi Arabia. \\ ${ }^{2}$ Princess Dr. Najla Bint Saud Al-Saud Center for Excellence Research in Biotechnology, King Abdulaziz University, Jeddah, Saudi Arabia. \\ Correspondence Author: Abdullah Aljaddawi, Department of Biological Sciences, Faculty of Science; King Abdulaziz University, Jeddah, Saudi Arabia. \\ E-mail:- aaljaddwi@kau.edu.sa
}

Received date: 11 August. 2019, Accepted date: 11 Nov. 2019, Online date: 15 November 2019

Copyright:2019 @ Abdullah Aljaddawi, This is an open-access article distributed under the terms of the Creative Commons Attribution License, which permits unrestricted use, distribution, and reproduction in any medium, provided the original author and source are credited.

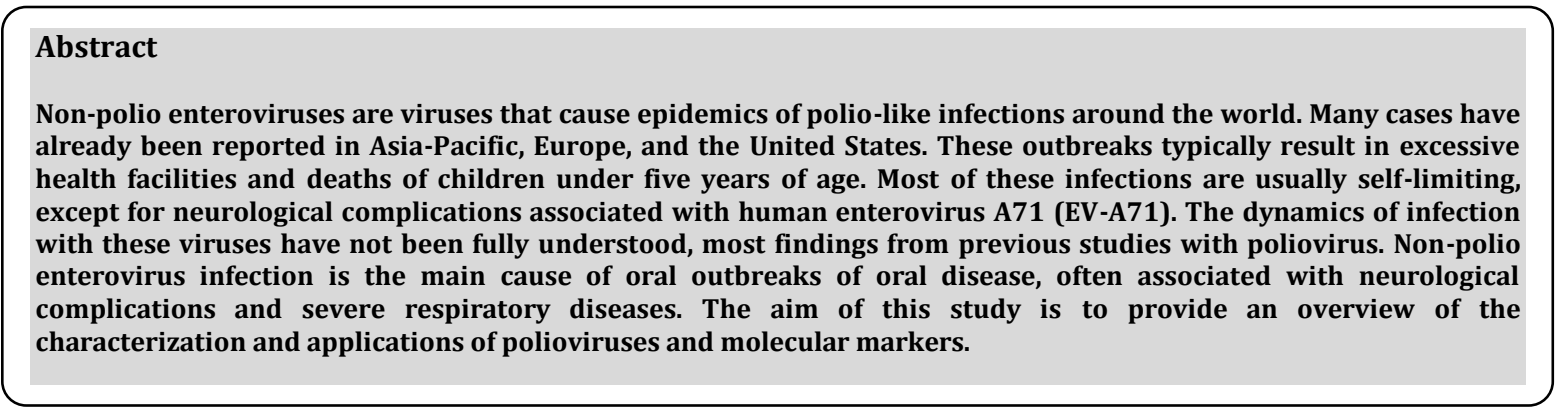

Keywords: Polio, Polioviruses, Molecular, Marker, DNA, Applications.

\section{INTRODUCTION}

In 1989, an epidemic of 10 cases of polio was in Saudi Arabia. Wild poliovirus type 1 was isolated in 5 patients. To determine the poliovirus circulation pattern, we compared the partial nucleotide sequences of the poliovirus isolates. These escapes were wonderful. Diversified the two isolates were closely related to each other and to the viruses isolated during the Oman epidemic in 1988. The other two isolates were very similar to the viruses found in Egypt. The fifth isolation was remote compared to the last pair. Molecular data shows that in 10 cases there were three different fires. Biological discoveries highlight the potential of Saudi Arabia, which receives millions of migrant workers and their families from polygenic countries every year with frequent imports of wild poliovirus. Saudi Arabia needs to maintain a majority population in all geopolitical units in order to limit the spread of imported polioviruses. In 1985, the Pan American Health Organization adopted the objective of regional wild poliovirus eradication in 1990[1] and the goal of eradicating shells was adopted by the World Health Assembly in 1988. For the 2000[2] year. The eradication of poliomyelitis has made significant progress. With the onset of stroke in September 1991, the Western Hemisphere recorded its last case in Peru [3]. The International Commission then certified the United States without children in August 1994[3]. The eradication of poliomyelitis in other countries and regions [4-7], including China [8, 9], Vietnam [10] and the Philippines [11], has made significant progress. For monitor progress towards polio eradication, certain metrics and process outcomes are used $[12,13]$. One of the most significant indicators distinguishes wild poly-virus numbers and molecular characteristics [14,15]. As the geographic area moves towards polio eradication, reservoirs of poliovirus are gradually disappearing and the remaining genotypes of poliovirus are reducing biodiversity, thus reducing the heterogeneity of the population. Poliovirus separate genomic sequences [15].

In 1989, there was an epidemic in the Gizan emirate in Saudi Arabia of 10 cases of paralytic polio in children with a high level of vaccination. The epidemic occurred despite a high level of coverage in the previous year with three doses of oral polio vaccine (OPV) given to children 1 year of the emirate. In order to complete the descriptive epidemiological studies[16] and seroprevalence studies $[17,18]$ of this outbreak, we tried to determine the relationships between the focused cases by analyzing the relationships of nucleotide sequence between isolated poliovirus cases of type 1.The epidemic was unexpectedly complex and 
includes three distinct wild poliovirus lines, two of which are endemic viruses in neighboring countries [18]. The aim of this work is an overview of polioviruses characterizations and molecular markers and their applications.

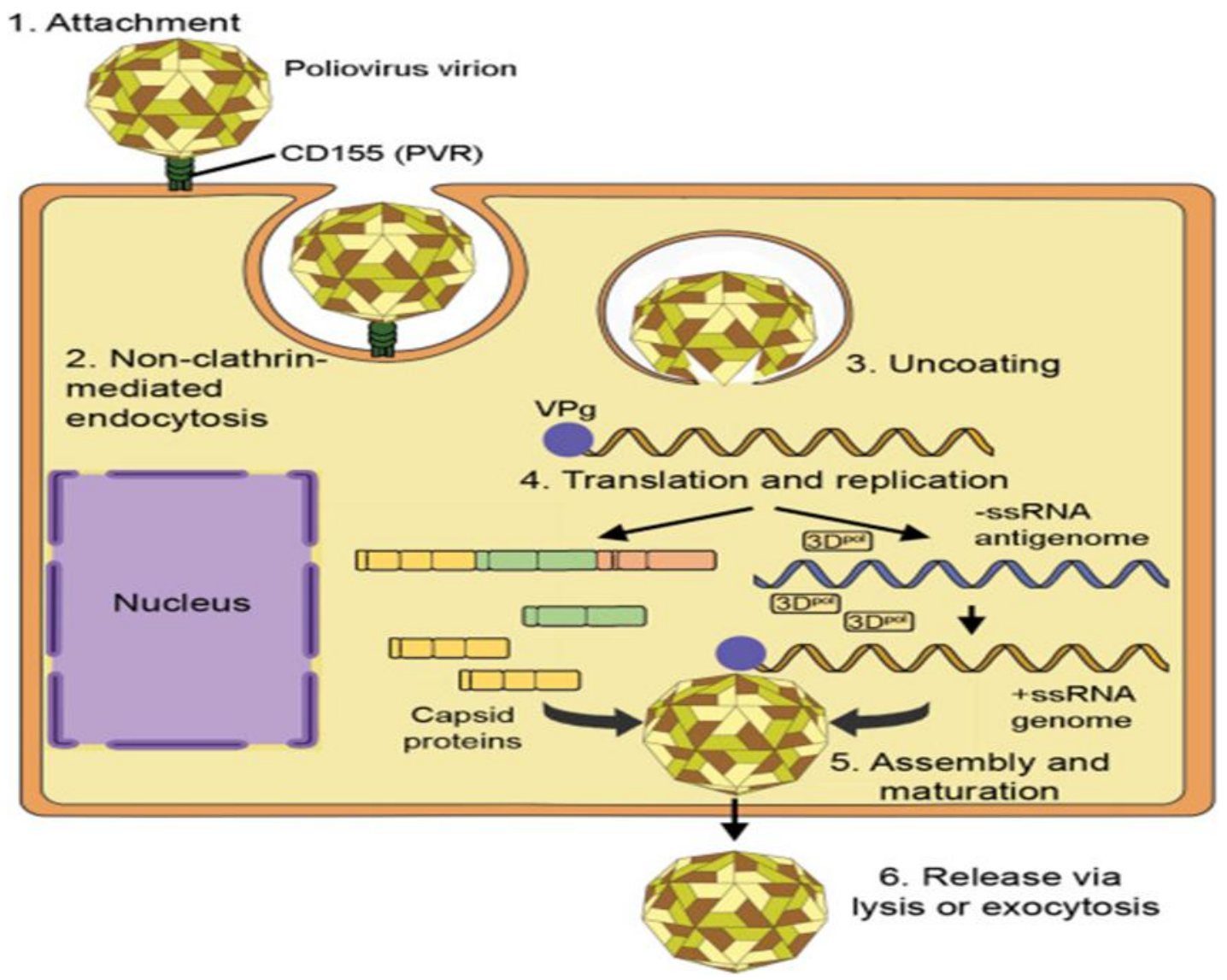

Fig 1. Poliovirus [19].

\section{The polio eradication end game: what it means for Europe}

This edition of Euro surveillance offers a series of articles on polio presenting the microcosm of some of the problems that have led to the eradication of polio since the program's inception. Most solutions, have these problems and others been clearly understood 1988 When the World Health Council approves the decision to abolish poliomyelitis by the year 2000, the decision to eliminate all countries will be more difficult? But luckily, the eradication of smallpox has spoiled recent success, the active discussion on the use of live or inactive polio vaccines, the realization that many countries have already when polio interrupted the transfer and she was unaware of the latest difficult eradication game, the decision was unanimously adopted by the member states of the World Health Organization (WHO) [20]. Despite the progress, eradication was slower than expected in 1988 and paralytic poliomyelitis increased from about 1,000 children per day in 1988 to about 400 in 2013 . Only three countries are left today. The recent risk assessment of endemic poliomyelitis, Afghanistan, Nigeria, and Pakistan, as well as the European Disease Prevention and Control Center (ECDC), reminds us that Europe must remain vigilant in terms of continuous laboratory monitoring and capacity [21]. The series of polio articles in this edition are described in Hindiyeh et al. [22] to describe direct testing of wild poliovirus antigen wastewater using quantitative reverse transcription multiplex PCR (qRT-PCR) in direct concentrated water samples for rapid virus detection. Similar to the cell culture of the same sewage specimens, the first standard test procedure for verification of polio, the sensitivity and specificity of the multiplex process has been shown to be high. Instead of the five to seven days needed for a culture-based procedure, results were obtained within 24 to 48 hours. The delay between stool sampling and poliovirus studies was typically several weeks in poliomyelitis eradication programs, but several days. The response, broader transmission, and greater and more expensive efforts to remain. Recently, the time between sampling and epidemic control has been significantly reduced by strengthening laboratory field transport systems and changing testing protocols [23]. At the same time, rapid results can be achieved through active research and development of new testing algorithms [24]. Hindiyeh et al. concluded that the qRT-PCR system could be a promising application for RNA tests directly extracted from treated stool samples in children with acute flashback paralysis (AFP). Further studies are not available in these studies [22]. Manor et al. [23, 25, 26] describe the discovery of a silent entry of wild poliovirus, which they describe as an early warning system to monitor the flow of poliovirus when AFP is not detected in children (standard surveillance Method). They found that this silent entry occurred in an immunized population in which the inactive poliomyelitis vaccine (IPV) has been used exclusively since 2005, and only AFP monitoring does not detect this entry and this cycle. The authors argue that environmental monitoring plays an important role in routine surveillance as a more sensitive early warning system for AFP in countries other than children. Shulman et al. [Information] provide more information on their reports on gene sequencing. The wild poliovirus they say was associated with tribes in South Asia and Egypt in 2012 and concluded that there were one or more significant events. In fact, many countries have spent the last ten years monitoring environmental wasting and identifying wild poliovirus imported from Switzerland in 2007 and 
some developing countries such as Egypt and India imported from Pakistan in 2007 [27, 28]. Environmental surveillance is the mainstay of polio eradication, and polio eradication is playing an increasingly important role in finals, to be evaluated [29, 30].

\section{Hajj vaccinations facts, challenges, and hope}

The Hajj is a unique collective event that is associated with increased public health risks in the host country (Saudi Arabia, KSA) and worldwide. The risks of concomitant infectious diseases include airborne infections, foodborne diseases, bloodborne diseases, and zoonotic infections. [31,32] Vaccination is one of the most important preventive measures to prevent infection and to control the transmission of infectious diseases. Vaccination has reduced the overall morbidity and mortality of many infectious diseases, and according to the World Health Organization (WHO), 2.5 million people are protected from infection each year. In addition, some vaccines not only protect individuals with the vaccine but also have unrelated contacts and contribute to community safety or the development of collective immunity. [33] Furthermore, there is increasing evidence that bacterial and viral vaccines may control the occurrence and spread of antibiotics [34-36]. Currently accepted vaccines can be divided into five main types: passive, lively attenuating vaccines, subunits, colloidal and conjugated vaccines. The nature of the vaccine determines its mechanism, including inhibiting the transmission of the pathogen, inhibiting resistance and reproduction, or decreasing the progression and severity of the disease, [37] current Hajj vaccine Policy. This includes mandatory vaccination of all pilgrims against meningococcal infection. [38 -40]. It adds compulsory vaccination against yellow fever and polio to pilgrims from endemic areas. Saudi Health Ministry strongly recommends vaccinating all pilgrims against seasonal flu, especially those at high risk for infectious complications. The impact of current vaccination policies on controlling the transmission of infectious diseases in this unique hajj pilgrimage environment is discussed here. In addition, we analyze how research can identify elements of future Hajj vaccination strategies and identify gaps in the scientific knowledge needed to improve the development and dissemination of vaccination strategies [40].

\section{Rapid Diagnosis of Poliovirus Infection by PCR Amplification}

Enteroviruses, including poliovirus, Coxsackie virus, echovirus and more recently enteroviruses [41], are among the most important and important viral pathogens in humans. The surveillance of active paralysis and diagnosis in the poliomyelitis laboratory is an essential element of the decision to proclaim polyolefin for the year 2000 [42, 43] so it is necessary that there are rapid techniques available. and reliable to differentiate polioviruses from non-polio enteroviruses. The diagnosis of enterovirus infection is even more dependent on the cells. culture techniques [44], enterovirus techniques by neutralization [45], long and expensive techniques. The differentiation between poliovirus and nonpolio poliovirus by microneutralization or immunofluorescence with poliovirus-specific antisera is less expensive but still takes a long time. Recently, mouse L cells transfected with the poliovirus receptor were developed for selective isolation of poliovirus and exclusion of other enteroviruses $[46,47]$. However, confirmation serotypes after isolation in cells and difficulties in maintaining cell lines (personal observation) prevent the routine use of these cells. PCR techniques have been used for the detection of enteroviruses in clinical specimens and supernatants of infected tissue cultures, well established [48-54]. However, the identification of poliovirus techniques for these techniques requires subsequent hybridization with poliovirus-specific probes or restriction enzyme analyte [55]. Poliovirusspecific PCR primers have been modified but cannot be detected strains of poliovirus [56] or several primer combinations must be simultaneous to obtain positive results [57]. This is a Rapid-Virus Detection on Rapid Test (PCR) in a single transverse reverse (RT) -PCR (RT-PCR) test in which a pair of primers is used. The test is sensitive (4 PFU) and very specific to poliovirus. as well the primers include the VP1-2A region used for genotype determination [58,59]. This technique allows the identification of poliovirus, differentiation of other enteroviruses in $24 \mathrm{~h}$ and determination of wild-type poliovirus genotypes by direct sequencing of PCR products. 


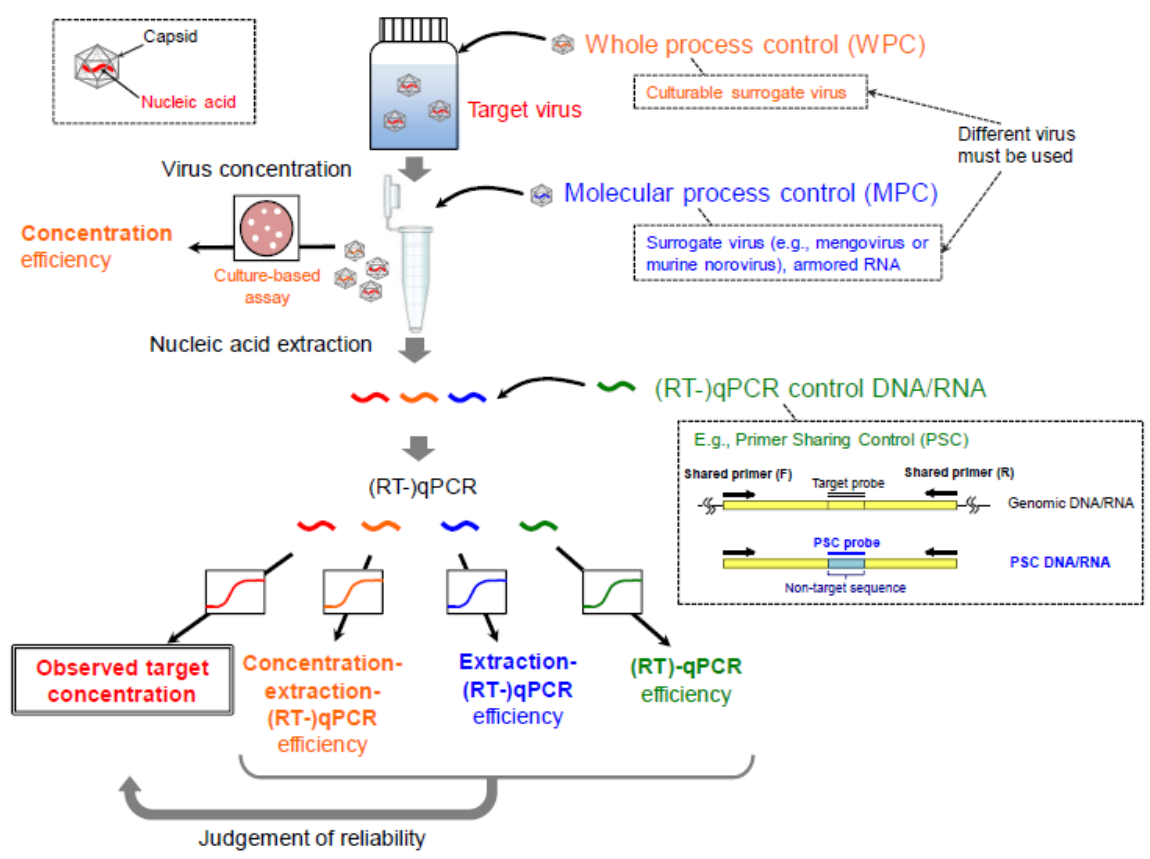

Fig. 2. The framework of process controls used during a virus detection procedure in water [60].

\section{Serotype-Specific Identification of Polioviruses by PCR}

The World Health Organization has set the year. The year 2000 was set as the deadline for global eradication of wildtype poliovirus [61]. There has been significant progress towards this goal [62]. In anticipation of polio eradication, there is growing interest due to increased surveillance of wild poliovirus [63] and virological elements [64]. A sensitive method for the detection and identification of poliovirus in clinical and environmental samples [65]. Three serotypes of poliovirus were originally identified using a reactivity model with neutralizing antibodies [66]. Standard methods available to produce polyvinyl isolates are neutralization tests using specific groups containing specific antisera or enzyme-linked immunosorbent assays using specific antisera. There were also serological methods for intraspinal differentiation of individual serotype poliovirus isolates [67]. Serological methods are generally reliable, but many specific antisera needs to be prepared and properties are discussed but are not consistent. Monoclonal antibody panel. In recent years, serological approaches have been complemented by many powerful molecular methods. Most nonpolar enteroviruses (NPEV) can selectively generate polioviruses in recombinant mouse cells that contain human poliovirus receptors [68]. Alternatively, poliovirus can be distinguished from NPEV by PCR assay with poliovirus specific primers [69]. For routine diagnosis, RNA probes and specific PCR primers that recognize isolates related to the Sabine vaccine [70] or various wild poliovirus genotypes [71] were developed. Poliovirus isolates were also identified by analyzing restriction fragment length polymorphisms of the amplified product with extended primers. Molecular methods usually have advantages such as high specificity, good selectivity, rapid productivity, and ease of use. Identification of poliovirus isolates is quick and easy when genotype-specific molecular reagents are available. Does not require a virus. However, many specific probes and primers are not yet available for all modern genotypes of wild-type poliovirus [72]. Wild polioviruses can be identified by excluding Sabina with certain molecular reagents, but this approach relies on the exact typing of virus isolates. In conclusion, we would like to develop a method to quickly identify poliovirus serotypes using PCR. We developed an approach [69, 73] that was previously adopted to develop PCR-specific primers for PCR, but not between degenerate PCR primers for the VP1 codon of the amino acid sequence. It is stored in the poliovirus serotype. This report describes the properties and possible uses of PCR primers specific for poliovirus serotypes.

\section{What Is the Relationship Between Outdoor Time and Physical Activity?}

High physical activity and even lifestyle are a global problem. Independent data from 39 countries show that only $23 \%$ and $19 \%$ of children aged 11 to 13 are exposed to 60 to 60 minutes of moderate to high recommended physical activity [74]. Objectively measured activity data suggest that among Canadian boys between the ages of 6 and 10,14\% of boys and $7 \%$ of girls follow recommendations and spend an average of 7.4 hours a day [75]. Data from 27 countries show a worldwide decline in children's performance during 20-m transportation testing in recent decades [76]. Consistent with these trends, evidence suggests that the current generation of children play less and less on the road than the generation of their parents [77,78]. It has been suggested that children's physical activities range primarily from unstructured, uncontrolled outdoor play to structured, controlled activities occurring indoors $[79,80]$. Some common parenting techniques are partly responsible for this change. Prioritization of educational outcomes [81.82] and the tendency of middle-class parents to participate in coordinated improvement in the ecosystem: engaging children in an abundance of additional enrichment activities left them at an unstructured moment [83, 84] Gone. The greatest concern for the safety of children (injuries, strangers, gangs and other threats) [ 85-86] can also be a driving force. Children inside. Some children like to play outside when they like [87-88] while others say that they are interested in indoor activities such as watching TV, such as watching TV, playing video games, using the Internet, Listen and read music, art [89]. This is probably partly due to the changing nature of children's social environments, which appear on the screen more rapidly 
outside [90]. Some researchers have suggested that spending long periods of time can be an effective strategy to limit sitting habits and increase physical activity and fitness in children [91, 92]. However, researchers often refer to cross-sectional studies, if any, indicating an external relationship. Recent studies have described outdoor time as one of several associations of children's behavior during physical activity [93-95]. However, none of these reviews is beyond the identification of classes that do not provide enough evidence for a causal link between outdoor and physical activity. To our knowledge, the relationship between outdoor time, physical fitness, and children's physical inactivity have not been systematically studied. The aim of this study is, therefore, to systematically review and assess the relationship between nature and time: (1) physical activity, (2) cardiorespiratory training, (3) musculoskeletal training, (4) passive behavior; And (5) development of motor skills in 3- to 12-year-old children. Our study included cross-sectional studies as well as prospective and experimental studies.

\section{Recent advances on the role of host factors during non-poliovirus enteroviral infections}

Non-polygomial enteroviruses belong to the genus Enterovirus (more than 15 species). It has been identified in the Picornaviridae family [96] and in various parts of the world, affecting the human population [97]. In the Asia-Pacific region, Europe, Canada, and the United States (USA) have recently reported serious outbreaks of non-potential virus infections. These infections occur when the world is trying to destroy them. In some parts of the world, there are very few cases of polio [98]. The severity of these infections is felt in children under 5 years of age. Most of them just started in the early days of school. It is well known that most of these infections are limited to them. However, in some cases, severe neurological complications and even death have been reported. A brief introduction to the epidemiology and pathogenesis of poliovirus. Therefore, the correlation between protein and host virus will be revealed at subsequent intervals and will need to be corrected in the future. The ability of various NPEV viruses to localize cell division, autophagy, and various cellular processes such as apoptosis, necroptosis, and pyrotosis is also emphasized for replication. Study of the state of antiviral treatment. Briefly describe these viruses and highlight existing gaps. It also highlights the prospects and areas of interest. Initially, enterovirus infection with non-poliovirusA-71 (EVA71) was isolated from fecal and cervical specimens of patients with complications of the central nervous system in California. Since then, Foot-and-mouth disease has been linked with the EV-A71 virus. It is normally characterized by spontaneous loss of immunity, acute stroke, and acute encephalitis types [99-102]. Throughout foot-and-mouth infection, the Cocciava A16 virus (CV-A16) plays an important role. $\mathrm{Xu}$ and colleagues have reported cases of renal failure after AB-A71 infection [103]. Cases of renal failure after EV-A71 infection have also been reported [104, 105]. MDF outbreaks have been reported in various regions of the Asia Pacific region. Children under the age of 5 suffer from neurological complications, especially in Singapore, especially in kindergartens [106]. For example, between 2008 and 2012, about 7.2 million people were registered in mainland China. The possible causes of MICEX and about 2,400 deaths lead to high economic costs [107]. This year, 34 cases of encephalitis / neurological complications after EV-A71 infection were reported in Colorado, USA [108]. The annual cycle of 2-3 outbreaks of foot-and-mouth disease in the Asia-Pacific region has been recorded [109]. In the United States, Pons-Salort and colleagues recently investigated the seasonality of NPEV, stating that July and September are the peak of these infections [110]. These outbreaks always cause overload, pain, and death of the health system in serious illnesses. The results of mathematical models using data from Singapore show a higher incidence of lifespan adjusted for disability (DALY) compared to other common infections in Asia. The southeast [111] represents the health potential of MMDG. World risk. Past sample analyzes have been conducted in seven West African countries to control poliovirus. In the movement area, multiple NPEVs were observed. The prevalent species are natural viruses [112]. The analysis also included less basic variables [ 112-113], such as [ EV-A 119],[ EVB75], [ CV-A20] and[ EV-D 94], typical in the art.

In West Africa, NEV classification and molecular characterization represents the global heterogeneity of these viruses, requiring a comprehensive monitoring system for better management and control. Main NPEV acquisition, capture and internalization factors / processes. Viral tissue tropism relies only on the receptors of the cells. It is responsible for the penetration and penetration of virus particles in host cells. The proteins of the human host serve as receptors for virus attacks and cell invasions and are involved in various virus infections in tissue tropism. Several receptors have been identified for several piconavarius; Poliovirus receptors were first discovered in this family. Regarding the late recovery of the enterovirus outbreak, all recent discoveries regarding the penetration of these viruses should be documented. Threshold indicator for further research. In binding, penetrating, and internalizing a viral infection, the conflict between viral proteins and human host proteins plays an important role. To enter susceptible cells and avoid the virus, different viruses use a limited number of receptors in the cell membrane. This process is important for potential virus genome spread and virus life cycle maintenance. This is one of the most commonly studied polioviruses among the picornaviruses. Based on these studies, numerous studies on enteroviruses and polioviruses have been performed. Some host factors have been identified as potential receptors for NPV, but the maximal dynamics of binding, penetration, and internalization have not been fully understood. Endocytosis, endocytosis, cytoskeletal dynamics, and clathrinids-mediated endosomal transport [114] have been shown to be an option to study EV-A71 to study the key genes involved in the study. A71 becomes sensitive cells. However, inhibition of endocytic pathways using chlorpromazine (CPZ) or dinosaur-induced clathrinid (DNA) shows a combination of EV cells, thereby preventing the entry of A549 cells. -A71. The virus is involved in the registration [115]. Host factors play an important role in the viral replication of the NPEV virus genome. Recent technological advances have played an important role in the discovery of a highly efficient genome for detecting interactions between human host factors. and steps associated with a viral infection. These methods have revolutionized the identification of host factors involved in viral infections. Cherry and Panda presented a siRNA genome detection method in which all major steps have been described in detail [116]. The detection of siRNA genomes has often been used in many studies to determine the human host's function. Factors of the infection with enterovirus. Wu and so on. Revision of the whole genome of siRNA and identification of several human host factors needed for infection with EV-A71[116]. This research identified susceptible host factors and resistant host factors involved in infection with EVA71; NGLY1 and CDK6 and AURKB, respectively, illustrate the important interaction between viral proteins and human host cell factors. 


\section{CONCLUSION}

The results of this study show that RT-PCR with primers PVPCR2 and 2A can be used for fast identify polioviruses and distinguish them from poliomyelitis enteroviruses and further characterization of poliovirus can be performed by direct sequencing of a PCR product generated by these primers.

\section{CONFLICT OF INTEREST}

The authors declare no conflicts of interest.

\section{ACKNOWLEDGMENT}

The author support from the department of biological sciences, faculty of Science, King Abdulaziz University, Jeddah, Saudi Arabia.

\section{REFERENCES}

[1] de Quadros CA, Andrus JK, Olive JM, de Macedo CG. Polio eradication from the Western hemisphere. Annu Rev Public Health 1992; 13:239- 52.

[2] World Health Assembly. Global eradication of poliomyelitis by the year 2000. Resolution of the 41st World Health Assembly. Geneva: World Health Organization, 1988; WHA 41.28.

[3] Centers for Disease Control and Prevention. Certification of poliomyelitis eradication-the Americas, 1994. MMWR Morb Mortal Wkly Rep 1994; 43:720-2.

[4] Centers for Disease Control and Prevention. Progress toward global poliomyelitis eradication, 1985-1994. MMWR Morb Mortal Wkly Rep 1995; 44:273-5,281.

[5] Yang B, Zhang J, Otten MW, et al. Eradication of poliomyelitis: progress in the People's Republic of China. Pediatr Infect Dis J 1995; 14:308-14.

[6] Centers for Disease Control and Prevention. Progress toward poliomyelitis eradication-People's Republic of China, 19901994. MMWR Morb Mortal Wkly Rep 1994; 43:857-9.

[7] Centers for Disease Control and Prevention. Progress toward poliomyelitis eradication-Socialist Republic of Vietnam, 1991-1993. MMWR Morb Mortal Wkly Rep 1994;43;387-91.

[8] Centers for Disease Control and Prevention. National polio immunization days and status of polio eradication-Philippines, 1993. MMWR Morb Mortal Wkly Rep 1994; 43:6-7, 13.

[9] Centers for Disease Control and Prevention. Progress toward poliomyelitis eradication-Egypt, 1993. MMWR Morb Mortal Wkly Rep 1994;43: 223-6.

[10] Centers for Disease Control and Prevention. Status of poliomyelitis eradication-Europe and the Central Asian Republics, 1993. MMWR Morb Mortal Wkly Rep 1994; 43:518-21.

[11] Centers for Disease Control and Prevention. Mass vaccination with oral poliovirus vaccine-Asia and Europe, 1995. MMWR Morb Mortal Wkly Rep 1995; 44:234-6.

[12] Expanded Programme on Immunization. Global polio eradication by the year 2000. Manual for managers of immunization programmes. Geneva: World Health Organization, 1989; WHO/EPVPOLIO/89.1.

[13] Andrus JK, de Quadros CA, Olive JM. The surveillance challenge: final stages of eradication of poliomyelitis in the Americas. MMWR CDC Surveill Summ 1992; 41:21-6.

[14] Rico-Hesse R, Pallansch MA, Nottay BK, Kew OM. Geographic distribution of wild poliovirus type 1 genotypes. Virology 1987; 160:311-22.

[15] Kew OM, Mulders MN, Lipskaya GY, da Silva EE, Pallansch MA. Molecular epidemiology of polioviruses. Semin Virol 1995; 6:401-14.

[16] Ramia S, Arif M. Paralytic poliomyelitis outbreak in Gizan, Saudi Arabia. J Trop Pediatr 1991; 37:202-4.

[17] Abanamy AM, Al Mazrou YY, Khalil MM, Al Jeffri MH, Abdelazeem MM. Seroprevalence of antibodies after vaccination against poliomyelitis. Saudi Med J 1992; 13:39-41.

[18] Huda Afif, Roland W. Sutter, Olen M. Kew, Robert E. Fontaine, Mark A. Pallansch, Mahesh K. Goyal, and Stephen L. Cochi (1997) Outbreak of Poliomyelitis in Gizan, Saudi Arabia: Cocirculation of Wild Type 1Polioviruses from Three Separate Origins, The Journal oflnfectious Diseases 1997; 175(Suppll):S71-5

[19] Stephanie B. Troy, Yvonne A. 2018. Maldonado, in Principles and Practice of Pediatric Infectious Diseases (Fifth Edition).

[20] Anis E, Kopel E, Singer SR, Kaliner E, Moerman L, Moran-Gilad J, et al. Insidious reintroduction of wild poliovirus into Israel, 2013. Euro Surveill. 2013;18(38): pii=20586.

[21] Hovi T, Shulman LM, van der Avoort H, Deshpande J, Roivainen M, DE Gourville EM. Role of environmental poliovirus surveillance in global polio eradication and beyond. Epidemiol Infect. 2012;140(1):1-13. http://dx.doi.org/10.1017/ S095026881000316X

[22] World Health Organization (WHO). Best practices for communicating with the public during an outbreak. Report of the WHO Expert Consultation on Outbreak Communications held in Singapore, 21-23 September 2004. Geneva: WHO. 2005.

[23] World Health Organization (WHO). World Health Organization Outbreak Communication Planning Guide. Geneva: WHO. 2008. 
[24] State of Israel Ministry of Health. News and Events. Press Releases. Polio Virus Detected in the Sewerage System of Rahat. 28 May 2013.

[25] Duncan B. How the media reported the first days of the pandemic (H1N1) 2009: results of EU-wide media analysis. Euro Surveill. 2009;14(30): pii=19286.

[26] Betsch C. Innovations in communication: The Internet and the psychology of vaccination decisions. Euro Surveill. 2011;16(17): pii=19849.

[27] Kata A. A postmodern Pandora's box: anti-vaccination misinformation on the Internet. Vaccine. 2010;28(7):1709-16.

[28] Baleta AF, van den Heever J, Burnett RJ. Meeting the need for advocacy, social mobilisation and communication in the introduction of three new vaccines in South Africa - successes and challenges. Vaccine. 2012;30 Suppl 3:C66-71.

[29] Levine H, Balicer RD, Laor D, Grotto I. Challenges and opportunities in the Israeli 2009 pandemic influenza vaccination program. Hum Vaccin. 2011;7(10):1077-82.

[30] Heymann D, Ahmed Q. The polio eradication end game: what it means for Europe. Euro Surveill. 2014;19(7):pii=20702.

[31] Ahmed QA, Arabi YM, Memish ZA. Health risks at the Hajj. Lancet 2006;367: 1008-15.

[32] World Health Organization. World Bank. State of the world's vaccines and immunization, 3rd ed., Geneva: WHO; 2009.

[33] Andre FE, Booy R, Bock HL, Clemens J, Datta SK, John TJ, et al. Vaccination greatly reduces disease, disability, death and inequity worldwide. Bull World Health Organ 2008; 86:140-6.

[34] Dagan R, Klugman KP. Impact of conjugate pneumococcal vaccines on antibi-otic resistance. Lancet Infect Dis 2008; 8:785-95.

[35] Cohen R. Approaches to reduce antibiotic resistance in the community. Pediatr Infect Dis J 2006; 25:977-80.

[36] Kwong JC, Maaten S, Upshur RE, Patrick DM, Marra F. The effect of universal influenza immunization on antibiotic prescriptions: an ecological study. Clin Infect Dis 2009; 49:750-6.

[37] Siegrist CA. Vaccine immunology. In: VaccinesSixth, Elsevier; 2013: 14-32.

[38] Memish ZA, Al Rabeeah AA. Health conditions for travellers to Saudi Arabia for the Umra and pilgrimage to Mecca (Hajj) -2014. J Epidemiol Glob Health 2014; 4:73-5.

[39] WHO. Health conditions for travellers to Saudi Arabia for the pilgrimage to Mecca (Hajj), 2015. Wkly Epidemiol Rec 2015;90(31):381-92.

[40] Moataz Abd El Ghany, Hazem Sharaf, Grant A. Hill-Cawthorne Hajj vaccinations-facts, challenges, and hope International Journal of Infectious Diseases, 47 (2016) 29-37.

[41] Melnick, J. L. 1990. Enteroviruses: polioviruses, coxsackieviruses, echoviruses, and newer enteroviruses, p. 549-605. In B. N. Fields and D. W. Knipe (ed.), Virology, 2nd ed. Raven Press, New York.

[42] World Health Organization. 1988. Global eradication of poliomyelitis by the year 2000. Weekly Epidemiol. Rec. 63:161168.

[43] World Health Organization. 1990. Global poliomyelitis eradication by the year 2000. Expanded programme on immunization and division of communicable diseases. World Health Organization, Geneva.

[44] Lennette, E. H. (ed.). 1992. Laboratory diagnosis of viral infections, 2nd ed. Marcel Dekker, Inc., New York.

[45] Lim, K. A., and M. Benyesh-Melnick. 1969. Typing of viruses by combination of antiserum pools. Application to typing of enteroviruses (coxsackie and echo). J. Immunol. 84:309-317. 9a. Maselesele, E. Personal communication.

[46] Hovi, T., and M. Stenvik. 1994. Selective isolation of poliovirus in recombinant murine cell line expressing the human poliovirus receptor gene. J. Clin. Microbiol. 32:1366-1368.

[47] Pipkin, P. A., D. J. Wood, V. R. Rancaniello, and P. D. Minor. 1993. Characterisation of L cells expressing the human poliovirus receptor for the specific detection of polioviruses in vitro. J. Virol. Methods 41:333-340.

[48] Chapman, N. M., S. Tracy, C. J. Gauntt, and U. Fortmueller. 1990. Molecular detection and identification of enteroviruses using enzymatic amplification and nucleic acid hybridization. J. Clin. Microbiol. 28:843-850.

[49] Hypia“, T., P. Auvinen, and M. Maaronen. 1989. Polymerase chain reaction for human picornaviruses. J. Gen. Virol. 70:3261-3268.

[50] Kämmerer, U., B. Kunkel, and K. Korn. 1994. Nested PCR for specific detection and rapid identification of human picornaviruses. J. Clin. Microbiol. 32:285-291.

[51] Muir, P., F. Nicholson, M. Jhetam, S. Neogi, and J. E. Banatvala. 1993. Rapid diagnosis of enterovirus infection by magnetic bead extraction and polymerase chain reaction detection of enterovirus RNA in clinical specimens. J. Clin. Microbiol. 31:31-38.

[52] Rotbart, H. A. 1990. Enzymatic amplification of the enteroviruses. J. Clin. Microbiol. 28:438-442.

[53] Thore 'n, A., A. J. Robinson, T. Maguire, and R. Jenkins. 1992. Two-step PCR in the retrospective diagnosis of enteroviral viraemia. Scand. J. Infect. Dis. 24:137-141.

[54] Yang, C. F., L. De, B. P. Holloway, M. A. Pallansch, and O. M. Kew. 1991. Detection and identification of vaccine-related polioviruses by the polymerase chain reaction. Virus Res. 20:159-179.

[55] Schweiger, B., F. Schreir, B. Bo "thig, and J. M. Lo 'pes-Pila. 1994. Differentiation of vaccine and wild-type polioviruses using polymerase chain reaction and restriction enzyme analysis. Arch. Virol. 134:39-50.

[56] Abraham, R., T. Chonmaitree, J. McCombs, B. Prabhakar, P. T. Lo Verde, and P. L. Ogra. 1993. Rapid detection of poliovirus by reverse transcription and polymerase chain reaction amplification: application for differentiation between poliovirus and non-poliovirus enteroviruses. J. Clin. Microbiol. 31: 395-399.

[57] Egger, D., L. Pasamontes, M. Ostermayer, and K. Bienz. 1995. Reverse transcription multiplex PCR for differentiation between polio- and enteroviruses from clinical and environmental samples. J. Clin. Microbiol. 33:1442- 1447.

[58] Rico-Hesse, R., M. A. Pallansch, B. K. Nottay, and O. M. Kew. 1987. Geographic distribution of wild poliovirus type 1 genotypes. Virology 160:311-322. 
[59] CLAUDIA CHEZZI Rapid Diagnosis of Poliovirus Infection by PCR Amplification, JOURNAL OF CLINICAL MICROBIOLOGY, July 1996, p. 1722-1725.

[60] Eiji Haramoto, Masaaki Kitajima, Akihiko Hata, Jason R. Torrey, Yoshifumi Masago, Daisuke Sano, Hiroyuki Katayama. A review on recent progress in the detection methods and prevalence of human enteric viruses in water, Water Research 135 (2018) 168e 186

[61] Hull, H. F., M. E. Birmingham, B. Melgaard, and J. W. Lee. 1997. Progress towards global polio eradication. J. Infect. Dis. 175(Suppl. 1): S4-S9.

[62] World Health Organization. 1996. Expanded Programmer on Immunization. Progress towards the global eradication of poliomyelitis, 1995. Weekly Epidemiol. Rec. 71:189-194.

[63] Birmingham, M. E., R. W. Linkins, B. P. Hull, and H. F. Hull. 1997. Poliomyelitis surveillance: the compass for eradication. J. Infect. Dis. 175 (Suppl. 1):S146-S150.

[64] Pinheiro, F. P., O. M. Kew, M. H. Hatch, C. M. da Silveira, and C. A. de Quadros. 1997. Eradication of wild polioviruses from the Americas: wild poliovirus surveillance-laboratory issues. J. Infect. Dis. 175(Suppl. 1):S43-S49.

[65] Van der Avoort, H. G. A. M., B. P. Hull, T. Hovi, M. A. Pallansch, O. M. Kew, R. Crainic, D. J. Wood, M. N. Mulders, and A. M. Van Loon. 1995. Comparative study of five methods for intratypic differentiation of polioviruses. J. Clin. Microbiol. 33:2562-2566.

[66] Bodian, D., I. M. Morgan, and H. A. Howe. 1949. Differentiation of types of poliomyelitis viruses. Am. J. Hyg. 49:234245.

[67] Nakano, J. H., M. H. Hatch, M. L. Thieme, and B. Nottay. 1978. Parameters for differentiating vaccine-derived and wild poliovirus strains. Prog. Med. Virol. 24:178-206.

[68] Hovi, T., and M. Stenvik. 1994. Selective isolation of poliovirus in recombinant murine cell line expressing the human poliovirus receptor gene. J. Clin. Microbiol. 32:1366-1368.

[70] Kilpatrick, D. R., B. Nottay, C.-F. Yang, S.-J. Yang, M. N. Mulders, B. P. Holloway, M. A. Pallansch, and O. M. Kew. 1996. Group-specific identification of polioviruses by PCR using primers containing mixed-based or deoxyinosine residues at positions of codon degeneracy. J. Clin. Microbiol. 34:2990-2996.

[71] Yang, C.-F., L. De, B. P. Holloway, M. A. Pallansch, and O. M. Kew. 1991.Detection and identification of vaccine-related polioviruses by the polymerase chain reaction. Virus Res. 20:159-179.

[72] Yang, C.-F., L. De, S.-J. Yang, J. R. Go'mez, J. R. Cruz, B. P. Holloway, M. A. Pallansch, and O. M. Kew. 1992. Genotype-specific in vitro amplification of sequences of the wild type 3 polioviruses from Mexico and Guatemala. VirusRes. 24:277-296.

[73] Kew, O. M., M. N. Mulders, G. Y. Lipskaya, E. E. da Silva, and M. A.

[74] Pallansch. 1995. Molecular epidemiology of polioviruses. Semin. Virol. 6:401-414.

[75] DAVID R. KILPATRICK, BALDEV NOTTAY, CHEN-FU YANG, SU-JU YANG, EDSON DA SILVA, SILVIA PEN ARANDA, MARK PALLANSCH, AND OLEN KEW Serotype-Specific Identification of Polioviruses by PCR Using Primers Containing Mixed-Base or Deoxyinosine Residues at Positions of Codon Degeneracy, JOURNAL OF CLINICAL MICROBIOLOGY, 1998, p. 352-357.

[76] Hallal, P.C.; Andersen, L.B.; Bull, F.C.; Guthold, R.; Haskell, W.; Ekelund, U. Global physical activity levels: Surveillance progress, pitfalls, and prospects. Lancet 2012, 380, 247-257.

[77] Colley, R.; Garriguet, D.; Janssen, I.; Craig, C.L.; Clarke, J.; Tremblay, M.S. Physical activity of Canadian children and youth: Accelerometer results from the 2007 to 2009 Canadian Health Measures Survey. Heal. Rep. 2011, 22 , 15-23.

[78] Tomkinson, G.R.; Léger, L.A.; Olds, T.S.; Cazorla, G. Secular trends in the performance of children and adolescents (1980-2000): An analysis of 55 studies of the 20 m shuttle run test in 11 countries. Sports Med. 2003, 33, $285-300$.

[79] Veitch, J.; Bagley, S.; Ball, K.; Salmon, J. Where do children usually play? A qualitative study ofparents' perceptions of influences on children's active free-play. Health Place 2006, 12, 383-393.

[80] Valentine, G.; McKendrck, J. Children's outdoor play: Exploring parental concerns aboutchildren's safety and the changing nature of childhood. Geoforum 1997, 28, 219-235.

[81] The Active Healthy Kids Canada 2012 Report Card on Physical Activity for Children and Youth; Active Healthy Kids Canada: Toronto, Canada, 2012.

[82] Lareau, A. Invisible inequality: Social class and childrearing in black families and white families. Amer. Sociol. Rev. 2002, 67, 747-776.

[83] Singh, A. Contexts of childhood and play: Exploring parental perceptions. Childhood 2012, 19, $235-250$.

[84] Wolf Fritz, R.; Smyrni, K.; Roberts, K. The challenges of bringing the waldkindergarten concept to North America. Child. Youth Environ. 2014, 24, 215-227.

[85] Carver, A.; Timperio, A.; Crawford, D. Playing it safe: The influence of neighbourhood safety on children's physical activity. A review. Health Place 2008, 14, 217-227.

[86] Clements, R. An investigation of the status of outdoor play-Contemporary issues in early childhood. Contemp. Issues Early Child. 2004, 5, 68-80.

[87] Holt, N.L.; Lee, H.; Millar, C.A.; Spence, J.C. "Eyes on where children play": A retrospective study of active free play. Child. Geogr. 2013, 13, 73-88.

[88] Glenn, N. Meanings of play among children. Childhood 2013, 20, 185-199.

[89] Miller, E.; Kuhaneck, H. Children's perceptions of play experiences and play preferences: A qualitative study. Amer. J. Occup. Ther. 2008, 62, 407-415. 
[90] Veitch, J.; Salmon, J.; Ball, K. Children's perceptions of the use of public open spaces for active free-play. Child. Geogr. 2007, 5, 409-422.

[91] Larson, L.R.; Green, G.T.; Cordell, H.K. Children's time outdoors: Results and implications of the National Kids Survey. J. Park Recreat. Adm. 2011, 29, 1-20.

[92] Skår, M.; Krogh, E. Changes in children's nature-based experiences near home: From spontaneous play to adultcontrolled, planned and organised activities. Child. Geogr. 2009, 7, 339-354.

[93] Ngo, C.S.; Pan, C.; Finkelstein, E.; Lee, C.; Wong, I.; Ong, J.; Ang, M.; Wong, T.; Saw, S. A cluster randomized controlled trial evaluating an incentive based outdoor physical activity programme to increase outdoor time and prevent myopia in children. Opthalmic Physiol. Opt. 2014, 34, 362-368.

[94] Barber, S.E.; Jackson, C.; Akhtar, S.; Bingham, D.D.; Ainsworth, H.; Hewitt, C.; Richardson, G.; Summerbell, C.D.; Pickett, K.E.; Moore, H.J.; Routen, A.C.; O’Malley, C.L.; Brierley, S.; Wright, J. "Pre-schoolers in the playground" an outdoor physical activity intervention for children aged 18 months to 4 years old: Study protocol for a pilot cluster randomised controlled trial. Trials 2013, 14, doi:10.1186/1745-6215-14-326.

[95] Hinkley, T.; Crawford, D.; Salmon, J.; Okely, A.D.; Hesketh, K. Preschool children and physical activity: a review of correlates. Amer. J. Prev. Med. 2008, 34, 435-441.

[96] Ferreira, I.; van der, H.K.; Wendel-Vos, W.; Kremers, S.; van Lenthe, F.J.; Brug, J. Environmental correlates of physical activity in youth-A review and update. Obes. Rev. 2007, 8, 129-154.

[97] Casey Gray, Rebecca Gibbons, Richard Larouche, Ellen Beate Hansen Sandseter Adam Bienenstock, Mariana Brussoni, Guylaine Chabot, Susan Herrington, Ian Janssen, William Pickett, Marlene Power, Nick Stanger, Margaret Sampson and Mark S. Tremblay. What Is the Relationship between Outdoor Time and Physical Activity, Sedentary Behaviour, and Physical Fitness in Children? A Systematic Review, Int. J. Environ. Res. Public Health 2015, 12, 6455-6474

[98] Zell R, Delwart E, Gorbalenya AE, Hovi T, King AMQ, Knowles NJ, et al. ICTV virus taxonomy profile: Picornaviridae. J Gen Virol. 2017; 98:2421-2.

[99] Palacios G, Oberste M. Enteroviruses as agents of emerging infectious diseases. J Neuro-Oncol. 2005; 11:424-33 Springer-Verlag.

[100] Endemic Countries - GPEI [Internet]. [cited 2018 Nov 6]. Available from: http://polioeradication.org/where-wework/polio-endemic-countries/

[101] Schmidt NJ, Lennette EHHH. An apparently new enterovirus isolated from patients with disease of the central nervous system. J Infect Dis. 1974; 129:304-9.

[102] Lum LC, Wong KT, Lam SK, Chua KB, Goh AY, Lim WL, et al. Fatal enterovirus 71 encephalomyelitis. J Pediatr. 1998; 133:795-8.

[103] Wasserstrom R, Mamourian AC, McGary CT, Miller G. Bulbar poliomyelitis: MR findings with pathologic correlation. AJNR Am J Neuroradiol. 1999;13: 371-3.

[104] Huang C-C, Liu C-C, Chang Y-C, Chen C-Y, Wang S-T, Yeh T-F. Neurologiccomplications in children with Enterovirus 71 infection. N Engl J Med. 1999; 341:936-42.

[105] Shen WC, Chiu HH, Chow KC, Tsai CH, Lee K-W, Huang S-C. MR imaging findings of enteroviral encephaloymelitis: an outbreak in Taiwan. AJNR Am J Neuroradiol. 2001; 20:1889-95.

[106] Cooper DJ, Shaw DR, LaBrooy JT, Blumbergs P, Gilbert J, Simmons A. Fatal rhabdomyolysis and renal failure associated with hand, foot and mouth disease. Med J Aust. 1989; 151:232-4.

[107] Zhou H-T, Wang B, Che X-Y. Nephrotic syndrome in hand, foot and mouth disease caused by coxsackievirus A16: a case report. Int J Infect Dis. 2014; 28:1-2.

[108] Xu Y, Wu YF, Luo HH, Zhang DD, Wu Y, Hu P. Acute kidney injury secondary to severe hand, foot and mouth disease caused by Enterovirus-A71: hypertension is a common. J Trop Pediatr. 2018.

[109] Ooi E-E, Phoon M-C, Ishak B, Chan S-H. Seroepidemiology of human enterovirus 71, Singapore. Emerg Infect Dis. 2002; 8:995-7 Centers for Disease Control and Prevention.

[110] Xing W, Liao Q, Viboud C, Zhang J, Sun J, Wu JT, et al. Hand, foot, and mouth disease in China, 2008-12: an epidemiological study. Lancet Infect Dis. 2014; 14:308-18.

[111] Messacar K, Burakoff A, Nix WA, Rogers S, Oberste MS, Gerber SI, et al. Notes from the Field: Enterovirus A71 neurologic disease in children — Colorado, 2018. MMWR Morb Mortal Wkly Rep. 2018; 67:1017-8.

[112] NikNadia NMN, Sam IC, Rampal S, WanNorAmalina WMZ, NurAtifah G, Verasahib K, et al. Cyclical patterns of hand, foot and mouth disease caused by Enterovirus A71 in Malaysia. PLoS Negl Trop Dis. 2016;10: e0004562 Williams M, editor. Public Library of Science.

[113] Pons-Salort M, Oberste MS, Pallansch MA, Abedi GR, Takahashi S, Grenfell BT, et al. The seasonality of nonpolio enteroviruses in the United States: patterns and drivers. Proc Natl Acad Sci U S A. 2018; 115:3078-83 National Academy of Sciences.

[114] Koh WM, Badaruddin H, La H, Chen MI-C, Cook AR. Severity and burden of hand, foot and mouth disease in Asia: a modelling study. BMJ Glob Heal. 2018;3:e000442 BMJ Publishing Group. 18. Fernandez-Garcia MD, Kebe O, Fall AD, Ndiaye K. Identification and molecular characterization of non-polio enteroviruses from children with acute flaccid paralysis in West Africa, 2013-2014. Sci Rep. 2017; 7:3808Nature Publishing Group.

[115] Collins Oduor Owino2 and Justin Jang Hann Chu Recent advances on the role of host factors during non-poliovirus enteroviral infections, Owino and Chu Journal of Biomedical Science (2019) 26:47.

[116] Hussain KM, Leong KLJ, Ng MM-L, Chu JJH. The essential role of Clathrinmediated endocytosis in the infectious entry of human Enterovirus 71. J Biol Chem. 2011; 286:309-21 
[117] Yuan M, Yan J, Xun J, Chen C, Zhang Y, Wang M, et al. Enhanced human enterovirus 71 infection by endocytosis inhibitors reveals multiple entry pathways by enterovirus causing hand-foot-and-mouth diseases. Virol J. $2018 ; 15: 1$.

[118] Panda D, Cherry S. A genome-wide RNAi screening method to discover novel genes involved in virus infection. Methods. 2015; 91:75-81 NIH Public Access. 